\title{
BMJ Open Concurrent drug use among methadone maintenance patients in mountainous areas in northern Vietnam
}

\author{
Bach Xuan Tran, ${ }^{1,2}$ Victoria L Boggiano, ${ }^{3}$ Huong Lan Thi Nguyen, ${ }^{4}$ \\ Long Hoang Nguyen, ${ }^{5}$ Hung Van Nguyen, ${ }^{6}$ Canh Dinh Hoang, ${ }^{6}$ Huong Thi Le, ${ }^{1}$ \\ Tho Dinh Tran, ${ }^{7}$ Hai Quan Le, ${ }^{8}$ Carl A Latkin, ${ }^{2}$ Thuc Minh Thi Vu, ${ }^{9}$ \\ Melvyn WB Zhang, ${ }^{10}$ Roger CM Ho ${ }^{11}$
}

To cite: Tran BX, Boggiano VL, Thi Nguyen $\mathrm{HL}$, et al. Concurrent drug use among methadone maintenance patients in mountainous areas in northern Vietnam. BMJ Open 2018;8:e015875. doi:10.1136/ bmjopen-2017-015875

- Prepublication history for this paper is available online. To view these files, please visit the journal online (http://dx.doi org/10.1136/bmjopen-2017015875).

BXT and VLB contributed equally.

Received 6 January 2017 Revised 18 December 2017 Accepted 19 December 2017

\section{ABSTRACT}

Objectives With the rise in methadone maintenance therapy (MMT) for drug users in Vietnam, there has been growing interest in understanding if and how often MMT patients engage in concurrent illicit drug use while on methadone therapy in various settings. This study examined factors associated with concurrent opioid use among patients on MMT in a mountainous area in Vietnam. Setting One urban and one rural MMT clinics in Tuyen Quang province.

Participants Survey participants consisted of patients who were taking MMT at the selected study sites. A convenience sampling approach was used to recruit the participants.

Primary and secondary outcome measures Participants were asked a series of questions about their socioeconomic status, current alcohol and tobacco use, health problems (measured by the EuroQol-Five Dimension-Five Level instrument), psychological distress (measured by Kessler score), and factors associated with current and/or previous drug use. Regression models were used to determine factors associated with concurrent drug use among MMT patients.

Results Among the 241 male MMT patients included in the study, $13.4 \%$ reported concurrent opioid use. On average, the longer patients had been enrolled in MMT, the less likely they were to concurrently use drugs. Conversely, patients with higher levels of psychological distress were more likely to engage in concurrent drug use while on MMT.

Conclusion Longer duration of MMT was significantly correlated with reduced illicit drug use among participants. Higher levels of psychological distress were associated with increased use of illicit drugs among MMT patients. Regardless of distance, long-term MMT is still effective and should be expanded in mountainous areas.

\section{INTRODUCTION}

Injection drug use is a pressing problem across Vietnam. The Vietnamese government cites the number of people who inject drugs (PWID) nationwide to be approximately 146 731. PWID are present in 90\% of the districts in Vietnam, highlighting the

\section{Strengths and limitations of this study}

- The study has a large number of individuals currently enrolled in methadone maintenance therapy (MMT) from mountainous settings in northern Vietnam.

- The study measures several aspects of patients' drug use behaviours, both before and during the MMT programme.

- A convenience sampling method was used, which limited the generalisability to all MMT patients in Vietnam.

widespread nature of this epidemic. They are at increased risk of contracting a variety of infectious diseases. ${ }^{1}$ Indeed, the majority of new HIV infections in Vietnam occur among injection drug users, ${ }^{2}$ and HIV-positive patients in Vietnam who use drugs have delayed access to care and generally poor adherence to antiretroviral treatment (ART) regimens. ${ }^{34}$

Methadone maintenance treatment (MMT) has shown significant promise as a way to reduce opiate addiction among PWID in Vietnam. MMT programmes in Vietnam have been extensively studied in recent years, and have been shown to reduce opiate use and other risk behaviours among enrollees, ${ }^{5-7}$ with a concurrent overall increase in patients' quality of life. ${ }^{4}$ These results are similar to what has been found with some MMT roll-out in other low-income/middle-income and developed countries across the globe. ${ }^{89}$ However, other researchers working in low-income/middle-income countries have found that even when patients are enrolled in MMT programmes, there remains an urgent need to address concurrent opioid use. ${ }^{10}$ The length of time using drugs may impact whether being enrolled in an MMT programme reduces illicit substance use. ${ }^{11}$ Alcohol and tobacco use, as well as psychiatric 
and other physical comorbidities, also impact whether or not an MMT programme is effective at reducing heroin use. Overall, more work is needed to fully elucidate the relationship between MMT programmes and concurrent drug use.

Among patients living with HIV/AIDS, MMT programmes have been shown to improve their access to and adherence with ART guidelines. ${ }^{12}$ The Vietnam Ministry of Health $(\mathrm{MoH})$ began to pilot the first national MMT programme for PWID in 2008, in an effort to both reduce illicit substance use and curb the HIV/AIDS epidemic in the country. ${ }^{13}$ Indeed, MMT programmes in Vietnam have been shown to drastically reduce concurrent opioid use among HIV-positive PWID. ${ }^{14}$ A study of Tran et $a l^{12}$ found that only $14.4 \%$ of MMT patients at clinics in two metropolitan areas had positive heroin urine test after 9 months of treatment. In addition, another study in Hanoi and Nam Dinh showed that with the mean treatment duration of 16.5 months, the rate of concurrent drug use among MMT patients was $4.8 \%{ }^{6}$ Higher age, poor health status and low socioeconomic status were previously found to be associated with the concurrent drug use. ${ }^{6}{ }^{12}$ However, none of them mention the effects of MMT on patients living in remote or mountainous sites, which may have distinguished barriers and cultures that influence the concurrent illicit drug use compared with the rural and urban areas.

We have implemented an evaluation of the MMT programme in Tuyen Quang, a mountainous province, to inform the development of strategic plan for expanding services in this area. We applied a system approach in health service research, which combined multiple services indicators and patients' responses. Some articles have been written using the same data set and made available examining different aspects of MMT from the patients' perspectives including health service use, stigmatisation and patients' adherence. ${ }^{15-17}$ Because of the potential benefits of MMT programmes in reducing drug use and improving patients' quality of life, there is increased attention being paid to the impact that enrolment has on their risk-taking behaviours. This study looked at factors associated with concurrent drug use among patients enrolled in MMT programmes in mountainous parts of northern Vietnam, to identify ways to best intervene and reduce illicit substance use among MMT patients in these regions.

\section{MATERIALS AND METHODS \\ Study setting and sampling method}

A cross-sectional study was carried out from May to August 2016 in Tuyen Quang province, a mountainous province in northern Vietnam. Tuyen Quang has more than 760000 people (2015) living in an area of $5867.9 \mathrm{~km}^{2}$. The dominant terrains in Tuyen Quang are hills, valleys and mountains (accounting for $80 \%$ of the area) ${ }^{18} \mathrm{In}$ Tuyen Quang province, three MMT clinics, namely Tuyen Quang City, Son Duong and Yen Son, have been opened.
Most of the patients were enrolled in the first two clinics, while only nine patients received treatment in the third clinic. All clinics are operated under the instruction of the MoH. ${ }^{19}$ First, opioid-dependent individuals may register to participate in the MMT programme by themselves or be referred to the clinics by physicians. After receiving health check-ups, blood and urine testing, and psychological counselling sessions, the patient's initial dose is identified. Then, the application form of the patient will be reviewed by a committee before having a final decision for enrolment. If the application is accepted, the patient starts to enrol in the MMT programme. In this study, Tuyen Quang City and Son Duong clinics were selected. The former clinic represents an urban part of the mountainous region, while the latter reflects the context of a more rural part.

Survey participants consisted of patients who were taking MMT at the selected study sites. The eligibility criteria included (1) taking or initiating MMT at the selected sites; (2) presenting at clinics during study periods; (3) being 18 years or older; (4) having the ability to answer the questionnaire within $20 \mathrm{~min}$; and (5) agreeing to participate in the study. A convenience sampling approach was applied, wherein all eligible clients were invited to enrol in the study and given written informed consent if they agreed to participate. Patients were invited to a private room in the clinic to ensure patient confidentiality and to create a more pleasurable atmosphere for the interview. All information from patients was assured to be kept confidentially. A convenience sample of 241 patients were enrolled in the study, and the response rate was $80 \%-90 \%$ across sites. Because only nine female patients enrolled in the MMT programme in two clinics and they refused to be participants, the sample of this study was $100 \%$ male.

\section{Measurements and instruments}

Well-trained interviewers including students in the Master of Public Health degree programme at the Hanoi Medical University conducted face-to-face interviews with all participants using a structured questionnaire. Health staffs of the centre were not included in the data collection team to prevent any social desirability bias. In drug use measurement, data from self-reported and urine drug test approaches had similar validity; therefore, self-report data can be used to collect information about drug use behaviours. ${ }^{20}{ }^{21}$ However, to minimise recall bias, some cross-check questions were employed to ensure the accuracy of self-reported information from patients, especially for primary outcomes.

\section{Socioeconomic characteristics}

Patients' age, gender, ethnicity, marital status, education level, employment status, religion and household monthly income were measured. Household monthly spending was measured in two ways: recurring/regular expenditures, including all money spent on food, clothes, rent, utilities, education and others in the last 30 days; and non-recurring/irregular expenditures, including 
healthcare costs, furniture, special occasions, travel and others incurred in the last 12 months. ${ }^{22-24}$

\section{Health status}

The EuroQol-Five Dimension-Five Level (EQ-5D-5L) instrument was used to measure patients' health-related quality of life. This descriptive system measures patients' well-being across five domains: mobility, self-care, usual activities, pain/discomfort and anxiety/depression, with five levels of responses: no problems, slight problems, moderate problems, severe problems and extreme problems. The scale thus gives 3125 health states with respective single indexes. The interim scoring for the EQ-5D-5L was computed using a cross-walk value set from Thailand, because such a metric is not available for Vietnamese patients. ${ }^{25}{ }^{26}$ The Vietnamese version of EQ-5D-5L was translated and adopted and has been validated elsewhere. ${ }^{16}{ }^{17}$ 26-32 Patients were also asked about their HIV status and whether they were suffering from any current acute or chronic diseases.

The Kessler Psychological Distress Scale was used to measure MMT patients' mental health. This is a well-validated tool that has been used among the Vietnamese-speaking population. ${ }^{33}$ It measures psychological distress using a 10-item questionnaire. Each question pertains to an emotional state, with a five-level response scale from 'None of the time' to 'All of the time'. The score ranges from 10 to 50 . The higher the score, the higher the patient's level of psychological distress.

\section{Alcohol habits}

The Alcohol Use Disorders Identification Test-Consumption (AUDIT-C) was used to screen patients for heavy drinking. ${ }^{35}$ The AUDIT-C contains three questions that lead to a band score of $(0 ; 12)$. The higher the score, the greater the risk of alcohol dependence. Male respondents who score 4 or higher and female respondents who score 3 or higher are categorised as hazardous drinkers. ${ }^{35}$ The Vietnamese version of this tool has been translated, validated and used elsewhere. ${ }^{36-38}$

\section{Smoking-related characteristics}

Participants who had smoked at least 100 cigarettes in their entire lives and had smoked within the last 30 days were classified as current cigarette smokers. ${ }^{39} 40$

Illicit drug use and rehabilitation

Data on participants' history of intravenous drug abuse, current drug use, patients' history of drug rehabilitation, reasons for relapse and whether family members used illicit drugs were also collected in this study. ${ }^{15} 31334142$

\section{MMT adherence}

We measured MMT adherence using the standard of MoH with three questions: (1) number of days that they missed doses in the last 4 days; (2) whether they missed doses in the last weekend; and (3) when they missed the last dose within the last 3 months. ${ }^{15}$ Patients were classified into 'optimal adherence' if they said 'No' to all
Table 1 Demographic characteristics of respondents

\begin{tabular}{lc} 
Characteristics & $\mathbf{n}(\%)$ \\
\hline Age group & \\
$<35$ & $55(22.8)$ \\
35 to $<50$ & $151(62.7)$ \\
$\geq 50$ & $35(14.5)$ \\
Gender & \\
$\quad$ Male & $241(100.0)$ \\
Education & \\
Primary school and below & $29(12.3)$ \\
Secondary school & $82(34.8)$ \\
High school & $106(44.9)$ \\
College/vocational training & $12(5.1)$ \\
University and above & $7(3.0)$ \\
Marital status & \\
Single & $54(22.9)$ \\
Live with spouse/partner & $147(62.3)$ \\
Divorced/separate & $27(11.4)$ \\
Widow & $8(3.4)$ \\
Employment & \\
Unemployed & $15(6.4)$ \\
Self-employed & $112(47.5)$ \\
Worker/farmer & $38(16.1)$ \\
Others & $71(30.1)$ \\
HIV-positive & $59(25.5)$ \\
Current antiretroviral treatment & $53(22.8)$ \\
Current smoker & $174(75.7)$ \\
Hazardous drinking & $44(18.3)$ \\
Having acute diseases & $53(22.0)$ \\
Having chronic diseases & $39(16.2)$ \\
Having problems in mobility & $33(14.0)$ \\
Having problems in self-care & $25(10.6)$ \\
Having problems in usual activities & $34(14.4)$ \\
Having pain/discomfort & $47(19.9)$ \\
Having anxiety/depression & $61(25.9)$ \\
\hline Total & $241(100.0)$ \\
\hline
\end{tabular}

questions; otherwise, they were identified as 'sub-optimal' adherence. $^{19}$

\section{Statistical analysis}

Data were analysed using STATA V.12.0 software. Student's t-test was used to assess differences of the parametric continuous variables between current and former drug users. $\chi^{2}$ and Fisher's exact tests were applied to determine differences among categorical variables. A P value $<0.05$ was considered statistically significant. For missing data, some authors argued that a rate of missing data under 5\% does not influence analysis. ${ }^{43}{ }^{44}$ In our study, the highest proportion of missing data was $4.6 \%$ for the 
Table 2 History of drug use among respondents

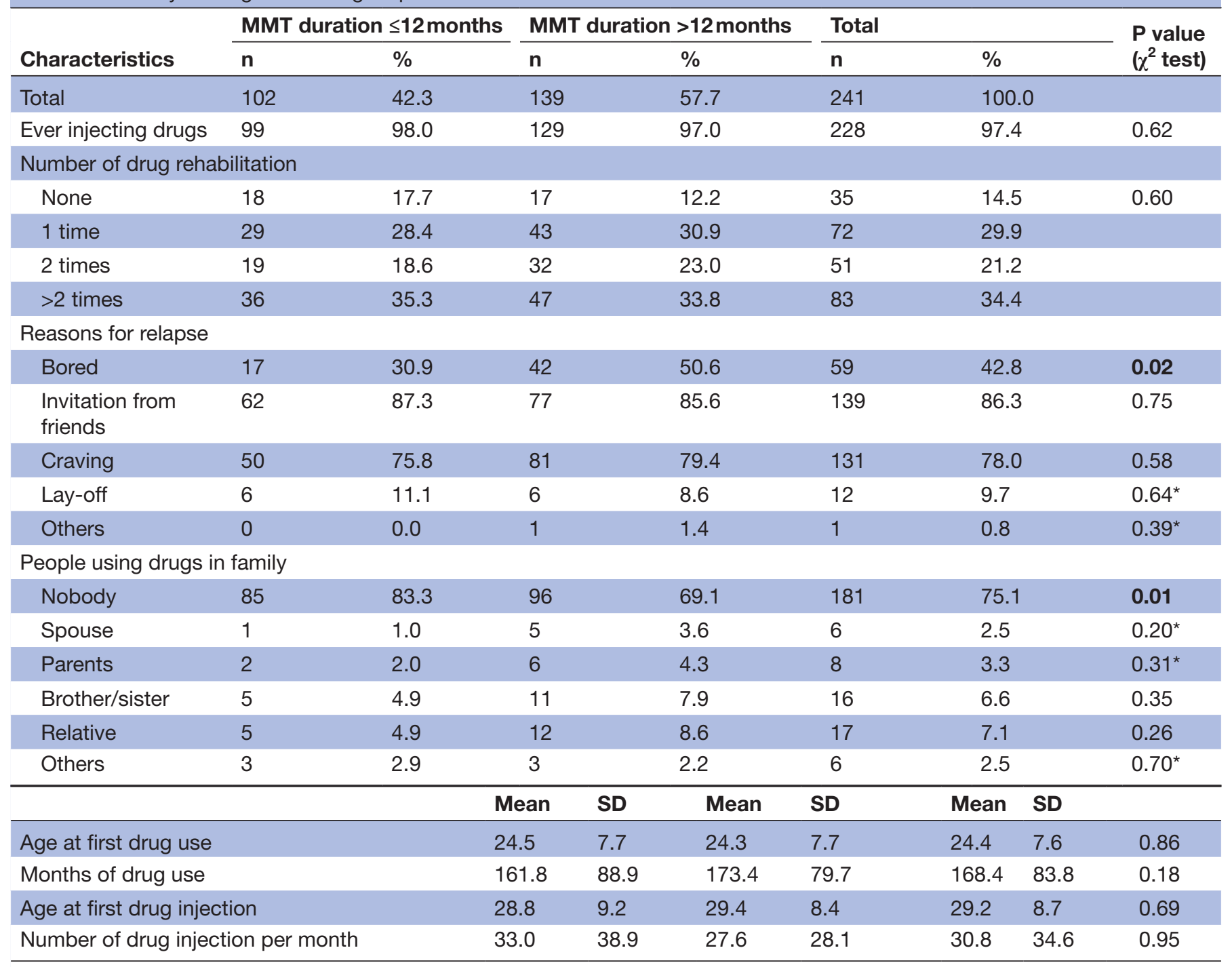

*Fisher's exact test.

MMT, methadone maintenance therapy.

$P$ value in bold is less than 0.05 .

variable current smoking, implying that our missing data rates can be ignored.

Logistic regression was used to identify the predictors of the outcome 'Concurrent drug use'. Meanwhile, Tobit regression was used to identify factors related to 'Non-drug using day'. Because the latter outcome is censored data (with range from 0 to 30 days), Tobit regression model, which is called censored regression, seemed to be appropriate for analysing this outcome. The full model included a priori-defined variables such as socioeconomic status, health status and behaviours. Stepwise backward selection strategies were employed to produce reduced models. A log-likelihood ratio test with a threshold $\mathrm{P}$ value $<0.2$ was used to exclude the variables.

\section{RESULTS}

Among 241 patients enrolled in this study, more than half of the respondents were living with spouse/partner
(62.3\%), finished high school and above $(53 \%)$, and were unemployed or had an unstable job (53.9\%). Current smokers accounted for $75.7 \%$ of the participants, and $18.3 \%$ were classified as hazardous drinkers. In addition, approximately a quarter of respondents were HIV-positive. A large proportion of patients suffered from at least one acute or chronic disease (table 1 ).

Table 2 shows that the majority of patients had injected drugs in the past $(97.4 \%)$ and were in drug rehabilitation programmes at least once $(85.5 \%)$. A large number of respondents relapsed due to the invitation from friends $(86.3 \%)$. Most of the respondents had relapsed due to friends $(86.3 \%)$ and craving $(78.0 \%)$.

Table 3 shows that among 232 patients answering this question, approximately $20 \%$ who had undergone less than 12 months of MMT treatment used drugs, which was significantly higher than other patients $(\mathrm{P}<0.05)$. Patients with concurrent drug use also had statistically significantly 
Table 3 Current drug use among respondents

\begin{tabular}{|c|c|c|c|c|c|c|c|}
\hline \multirow[b]{2}{*}{ Characteristics } & \multicolumn{2}{|l|}{ No } & \multicolumn{2}{|l|}{ Yes } & \multicolumn{2}{|l|}{ Total } & \multirow[b]{2}{*}{$P$ value } \\
\hline & $\mathbf{n}$ & $\%$ & $n$ & $\%$ & $\bar{n}$ & $\%$ & \\
\hline Total & 201 & 86.6 & 31 & 13.4 & 232 & 100.0 & \\
\hline \multicolumn{8}{|l|}{ Age group } \\
\hline$<35$ & 47 & 88.7 & 6 & 11.3 & 53 & 22.8 & 0.88 \\
\hline 35 to $<50$ & 128 & 85.9 & 21 & 14.1 & 149 & 64.2 & \\
\hline$\geq 50$ & 26 & 86.7 & 4 & 13.3 & 30 & 12.9 & \\
\hline \multicolumn{8}{|l|}{ Sex } \\
\hline Male & 201 & 86.6 & 31 & 13.4 & 232 & 100.0 & \\
\hline \multicolumn{8}{|l|}{ Education } \\
\hline Below high school & 90 & 82.6 & 19 & 17.4 & 109 & 47.0 & 0.14 \\
\hline High school & 97 & 91.5 & 9 & 8.5 & 106 & 45.7 & \\
\hline Above high school & 14 & 82.4 & 3 & 17.7 & 17 & 7.3 & \\
\hline \multicolumn{8}{|l|}{ Marital status } \\
\hline Single & 46 & 86.8 & 7 & 13.2 & 53 & 22.8 & 0.68 \\
\hline Live with spouse/partner & 124 & 85.5 & 21 & 14.5 & 145 & 62.5 & \\
\hline Divorced/separate/widow & 31 & 91.2 & 3 & 8.8 & 34 & 14.7 & \\
\hline \multicolumn{8}{|l|}{ Employment } \\
\hline Unemployed & 11 & 78.6 & 3 & 21.4 & 14 & 6.0 & 0.79 \\
\hline Self-employed & 97 & 88.2 & 13 & 11.8 & 110 & 47.4 & \\
\hline Worker/farmer & 33 & 86.8 & 5 & 13.2 & 38 & 16.4 & \\
\hline Others & 60 & 85.7 & 10 & 14.3 & 70 & 30.2 & \\
\hline HIV-positive & 49 & 83.1 & 10 & 17.0 & 59 & 26.0 & 0.54 \\
\hline ART treatment & 45 & 84.9 & 8 & 15.1 & 53 & 23.1 & 0.71 \\
\hline Current smoking & 146 & 85.4 & 25 & 14.6 & 171 & 75.7 & 0.65 \\
\hline Hazardous drinking & 40 & 90.9 & 4 & 9.1 & 44 & 19.0 & 0.36 \\
\hline Pain/discomfort & 42 & 89.4 & 5 & 10.6 & 47 & 20.3 & 0.54 \\
\hline Anxiety/depression & 52 & 85.3 & 9 & 14.8 & 61 & 26.3 & 0.71 \\
\hline \multicolumn{8}{|l|}{ MMT duration } \\
\hline$\leq 12$ months & 80 & 80.0 & 20 & 20.0 & 100 & 43.1 & 0.03 \\
\hline 12 to $<24$ months & 82 & 93.2 & 6 & 6.8 & 88 & 37.9 & \\
\hline$\geq 24$ months & 39 & 88.6 & 5 & 11.4 & 44 & 19.0 & \\
\hline \multicolumn{8}{|l|}{ MMT adherence } \\
\hline Optimal & 70 & 85.4 & 12 & 14.6 & 82 & 35.3 & 0.67 \\
\hline \multirow[t]{2}{*}{ Suboptimal } & 131 & 87.3 & 19 & 12.7 & 150 & 64.7 & \\
\hline & Mean & SD & Mean & SD & Mean & SD & \\
\hline$E Q-5 D$ index & 0.88 & 0.21 & 0.89 & 0.17 & 0.88 & 0.21 & 0.76 \\
\hline EQ VAS & 81.5 & 15.2 & 82.8 & 15.8 & 81.6 & 15.2 & 0.67 \\
\hline Kessler score & 15.8 & 6.4 & 18.4 & 7.1 & 16.2 & 6.6 & 0.04 \\
\hline
\end{tabular}

ART, antiretroviral; EQ-5D, EuroQol-Five Dimensions; EQ VAS, EuroQoL Visual Analogue Scale; MMT, methadone maintenance therapy. $P$-value in bold is less than 0.05 .

higher Kessler score than those not using drug $(\mathrm{P}<0.05)$. Meanwhile, none of the differences were found in other factors.

Table 4 shows the factors related to current drug use and the number of non-drug-using days among MMT patients, using the reduced multivariate logistic and Tobit regressions models. Those who finished high school or above were less likely to report current drug use. Duration of MMT was found to be associated with reduced likelihood of current drug use among those retained on MMT, while having higher Kessler scores (OR=1.08) $(95 \%$ CI 1.01 to 1.16) during MMT substantially increased the 
Table 4 Factors associated with current drug use among respondents

\begin{tabular}{|c|c|c|c|c|}
\hline \multirow[b]{2}{*}{ Characteristics } & \multicolumn{2}{|c|}{ Concurrent drug use } & \multicolumn{2}{|c|}{$\begin{array}{l}\text { Number of non-drug-using days in the last } \\
\text { month }\end{array}$} \\
\hline & OR & $95 \% \mathrm{Cl}$ & Coefficient & $95 \% \mathrm{Cl}$ \\
\hline \multicolumn{5}{|l|}{ Education (vs below high school) } \\
\hline High school & $0.31^{*}$ & 0.12 to 0.81 & & \\
\hline Above high school & & & -14.36 & -36.14 to 7.42 \\
\hline \multicolumn{5}{|l|}{ Number of drug rehabilitation (vs none) } \\
\hline 2 times & 2.13 & 0.73 to 6.24 & & \\
\hline ART treatment (yes vs no) & & & 9.93 & -2.81 to 22.67 \\
\hline Having problem in self-care (yes vs no) & 0.30 & 0.05 to 1.80 & & \\
\hline Pain/discomfort (yes vs no) & & & $24.35^{\star \star}$ & 6.44 to 42.26 \\
\hline Kessler score (range score 10-37) & $1.08^{*}$ & 1.01 to 1.16 & & \\
\hline MMT duration (from 1 to 38 months) & $0.92^{\star \star}$ & 0.87 to 0.98 & $0.99^{\star \star}$ & 0.32 to 1.66 \\
\hline
\end{tabular}

${ }^{*} \mathrm{P}<0.05,{ }^{* \star} \mathrm{P}<0.01$.

ART, antiretroviral; MMT, methadone maintenance therapy.

risk of current drug use. Having pain/discomfort was associated with fewer numbers of non-drug-using days, while longer duration of MMT was associated with greater numbers of non-drug-using days. Notably, MMT adherence was excluded from reduced models, implying that there was no relationship between MMT adherence and concurrent drug use.

\section{DISCUSSION}

This study highlights the factors that are associated with concurrent drug use among Vietnamese patients enrolled in an MMT programme in two clinics in northern Vietnam. Overall, being enrolled in MMT was associated with a decreased rate of illicit drug use. This finding is consistent with other similar studies in Vietnam and elsewhere. ${ }^{12} 45-47$ In our study, longer duration of enrolment in MMT was associated with less concurrent illicit substance use, while having a higher level of psychological distress during MMT enrolment was associated with a significantly increased rate of concurrent opioid abuse.

The HIV/AIDS epidemic in Vietnam is largely driven by illicit substance use, and the primary driver of new HIV infections nationwide is drug injection. It is therefore crucially important to devise strategies to reduce injection drug use in high-risk parts of the country. Our study shows that MMT programmes represent one primary solution to this problem. Individuals who engage in MMT programmes for longer durations show overall reduced rates of concurrent drug use. However, this study also found that many patients enrolled in MMT continue to use drugs $(13.4 \%)$. This rate was lower compared with MMT patients in other countries, such as China $(24.9 \%-74.6 \%),{ }^{10} 484$ USA $(44 \%)^{50}$ or Canada $(78.3 \%) .{ }^{51}$ However, this is in line with previous studies that have found that among MMT patients in Vietnam, the rates of concurrent drug use are often between $11 \%$ and $14 \% .^{13} 14$ There are several possible reasons for this phenomenon. First, northern mountainous provinces in Vietnam are considered epicentres of drug use; therefore, patients could access illicit drug easily. ${ }^{52}$ Second, drug users' social networks could continue to revolve around illicit substance use even when they enrol in MMT programmes, meaning patients may face pressure to continue using drugs with their peers. ${ }^{143}$ Third, the adherence of patients in mountainous settings might be low due to geographical barriers that diminish the accessibility of MMT clinics, which facilitates them to relapse. ${ }^{15}$

In the present study, higher Kessler scores-indicating higher levels of anxiety/depression and overall worse mental health-displayed greater rates of concurrent drug use alongside MMT. This result is not surprising; it has long been known that patients seek out illicit substance use when they are feeling depressed, sad or anxious. Indeed, past research looking at concurrent drug use among MMT patients found that patients with poor coping skills were more likely to engage in concurrent drug use. ${ }^{53}$

The study suggested several potential implications. First, to fully enable patients to break their drug addiction, in addition to enrolment in MMT, patients must be provided social and behavioural modification support, such as providing them with new educational and workforce opportunities. Moreover, the involvement of families is critical to encourage as well as support patients to release the pressure from their lives and help them to quit drug use, as previously mentioned in the literature. ${ }^{12}$ Second, our findings highlight the importance of improving mental healthcare services for drug-addicted patients, in addition to expanding MMT. MMT alone will help some patients quit injecting drugs, but for many others comprehensive care that includes both MMT and adequate mental health services is required to help them fully quit using drugs. Third, because commune health stations are the closest health facility for 
patients, ${ }^{29}$ decentralisation should be considered when planning the expansion of MMT programme. ${ }^{6}$ This solution could elevate the accessibility of treatment, eliminate the geographical barriers and facilitate the adherence, resulting in the abstinence of drug use among MMT patients. ${ }^{15}$

This study had several limitations. First, several important indicators such as methadone dose and stigma were not fully investigated in this study. Second, a convenience sampling method with a small sample size was used, which means that our findings may not be representative of all MMT patients in Vietnam, or at least MMT patients in other mountainous areas. Moreover, the self-reported approach was used to measure previous and current drug use, which might lead to recall bias if patients have a hard time remembering details of their substance use patterns. Several solutions were used to address this issue, such as not collecting patients' identity, assuring their confidentiality and recalling them to the events that associated with their latest drug use. Moreover, although we collected the methadone dosage, we could not include these data in the analysis because of low quality. Despite these limitations, our study sheds important light on factors associated with concurrent drug use among MMT patients in a mountainous area in northern Vietnam.

\section{CONCLUSION}

The findings highlighted in this study reveal the dramatic impact that MMT programmes can have on reducing illicit substance use among previously drug-addicted patients in Vietnam. Despite several existing limitations, this study highlights that MMT programmes should continue to be rolled out across Vietnam to reduce drug use, with a concurrent increase in the mental health services offered to these patients. Moreover, further studies should be warranted in a larger scale to fill the gaps in this study and to be sufficiently representative to apply across the nation.

\section{Author affiliations}

${ }^{1}$ Institute for Preventive Medicine and Public Health, Hanoi Medical University, Hanoi, Vietnam

${ }^{2}$ Bloomberg School of Public Health, Johns Hopkins Bloomberg School of Public Health, Baltimore, Maryland, USA

${ }^{3}$ Berkeley School of Public Health, University of California, Berkeley, California, USA

${ }^{4}$ Institute for Global Health Innovations, Duy Tan University, Da Nang, Vietnam

${ }^{5}$ School of Medicine and Pharmacy, Vietnam National University, Hanoi, Vietnam

${ }^{6}$ Authority of HIV/AIDS Control, Ministry of Health, Hanoi, Vietnam

${ }^{7}$ Department of Hepatobiliary Surgery, Vietnam-Germany Hospital, Hanoi, Vietnam

${ }^{8}$ Provincial AIDS Center, Department of Health, Tuyen Quang, Vietnam

${ }^{9} \mathrm{Center}$ for Research and Training, Tam Anh Hospital, Hanoi, Vietnam

${ }^{10}$ Biomedical Global Institute of Healthcare Research \& Technology (BIGHEART), National University of Singapore, Singapore

${ }^{11}$ Department of Psychological Medicine, Yong Loo Lin School of Medicine, National University of Singapore, Singapore

Acknowledgements We would like to thank the patients and their families for their participation in this study. We would also like to thank the Vietnam Authority of HIV/AIDS Control and the Tuyen Quang Provincial AIDS Center for their help and support.
Contributors VLB, HLTN, LHN, HVN, CDH, HTL, TDT, HQL, BXT, CAL and TMTV conceived of the study, and participated in its design and implementation and wrote the manuscript. VLB, HLTN and LHN analysed the data. RCH and MWZ edited the manuscript and provided their expert advice based on their medical specialists' knowledge. All authors read and approved the final manuscript.

Funding The authors have not declared a specific grant for this research from any funding agency in the public, commercial or not-for-profit sectors.

Competing interests None declared.

Patient consent Obtained.

Ethics approval This study's protocol was approved by the IRB of Vietnam Authority of HIV/AIDS Control. Data collection procedures were also approved by the directors of the MMT clinics. Written informed consent was obtained from all participants.

Provenance and peer review Not commissioned; externally peer reviewed.

Data sharing statement The data that support the findings of this study were made available by the Vietnam Authority of HIV/AIDS Control, but there were a few restrictions on the availability of these data. The data were used under licence for the current study, and so are not publicly available. Data are however available from the authors upon reasonable request and with permission from the Vietnam Authority of HIV/AIDS Control.

Open Access This is an Open Access article distributed in accordance with the Creative Commons Attribution Non Commercial (CC BY-NC 4.0) license, which permits others to distribute, remix, adapt, build upon this work non-commercially, and license their derivative works on different terms, provided the original work is properly cited and the use is non-commercial. See: http://creativecommons.org/ licenses/by-nc/4.0/

(c) Article author(s) (or their employer(s) unless otherwise stated in the text of the article) 2018. All rights reserved. No commercial use is permitted unless otherwise expressly granted.

\section{REFERENCES}

1. Mo H. The annual report of HIVIAIDS in 2011. Hanoi, Vietnam, 2012.

2. The Global Fund to Fight AIDS T, and Malaria. TB and HIV concept note. Viet Nam, 2014.

3. Wolfe D, Carrieri MP, Shepard D. Treatment and care for injecting drug users with HIV infection: a review of barriers and ways forward. Lancet 2010;376:355-66.

4. Wood E, Kerr T, Tyndall MW, et al. A review of barriers and facilitators of HIV treatment among injection drug users. AIDS 2008;22:1247-56.

5. Boggiano VL, Nguyen HLT, Nguyen LH, et al. Sexual behaviors among methadone maintenance patients in a mountainous area in northern Vietnam. Subst Abuse Treat Prev Policy 2017;12:39.

6. Tran BX, Nguyen LH, Nong VM, et al. Behavioral and quality-of-life outcomes in different service models for methadone maintenance treatment in Vietnam. Harm Reduct $J$ 2016;13:4.

7. Tran BX, Nguyen LH, Phan HT, et al. Preference of methadone maintenance patients for the integrative and decentralized service delivery models in Vietnam. Harm Reduct J 2015;12:29.

8. Connock M, Juarez-Garcia A, Jowett S, et al. Methadone and buprenorphine for the management of opioid dependence: a systematic review and economic evaluation. Health Technol Assess 2007;11:1-171. iii-iv.

9. Lawrinson P, Ali R, Buavirat A, et al. Key findings from the WHO collaborative study on substitution therapy for opioid dependence and HIV/AIDS. Addiction 2008;103:1484-92.

10. Li L, Lin C, Wan D, et al. Concurrent heroin use among methadone maintenance clients in China. Addict Behav 2012;37:264-8.

11. Dobler-Mikola A, Hättenschwiler J, Meili D, et al. Patterns of heroin, cocaine, and alcohol abuse during long-term methadone maintenance treatment. J Subst Abuse Treat 2005;29:259-65.

12. Tran BX, Ohinmaa A, Mills S, et al. Multilevel predictors of concurrent opioid use during methadone maintenance treatment among drug users with HIV/AIDS. PLoS One 2012;7:e51569.

13. Tran BX, Ohinmaa A, Duong AT, et al. The cost-effectiveness and budget impact of Vietnam's methadone maintenance treatment programme in HIV prevention and treatment among injection drug users. Glob Public Health 2012;7:1080-94.

14. Tran BX, Ohinmaa A, Duong AT, et al. Changes in drug use are associated with health-related quality of life improvements among methadone maintenance patients with HIV/AIDS. Qual Life Res 2012;21:613-23. 
15. Nguyen LH, Nguyen HTT, Nguyen HLT, et al. Adherence to methadone maintenance treatment and associated factors among patients in Vietnamese mountainside areas. Subst Abuse Treat Prev Policy 2017;12:31.

16. Nguyen LH, Nguyen LHT, Boggiano VL, et al. Quality of life and healthcare service utilization among methadone maintenance patients in a mountainous area of Northern Vietnam. Health Qual Life Outcomes 2017;15:77.

17. Van Nguyen $\mathrm{H}$, Nguyen $\mathrm{HL}$, Mai $\mathrm{HT}$, et al. Stigmatization among methadone maintenance treatment patients in mountainous areas in northern Vietnam. Harm Reduct $J$ 2017;14:1.

18. Authority TQ. Introduction to Tuyen Quang. Secondary introduction to Tuyen Quang. 2017 http://www.tuyenquang.gov.vn/tgt28p1_dieukien-tu-nhien-html

19. VMo H. Decision No 3140/QD-BYT on Guideline for Substance abuse treatment using methadone. Hanoi 2010.

20. Wilcox CE, Bogenschutz MP, Nakazawa M, et al. Concordance between self-report and urine drug screen data in adolescent opioid dependent clinical trial participants. Addict Behav 2013;38:2568-74.

21. Decker SE, Frankforter T, Babuscio T, et al. Assessment concordance and predictive validity of self-report and biological assay of cocaine use in treatment trials. Am J Addict 2014;23:466-74.

22. Lu C, Chin B, Li G, et al. Limitations of methods for measuring outof-pocket and catastrophic private health expenditures. Bull World Health Organ 2009;87:238-44.

23. Tran BX, Phan HT, Nguyen LH, et al. Economic vulnerability of methadone maintenance patients: Implications for policies on copayment services. Int J Drug Policy 2016;31:131-7.

24. Tran BX, Nguyen QL, Nguyen LH, et al. Expanding co-payment for methadone maintenance services in Vietnam: the importance of addressing health and socioeconomic inequalities. BMC Health Serv Res 2017;17:480.

25. Eqol G. EQ-5D-5L User Guide: Basic information on how to use the EQ-5D-5L instrument. Rotterdam, The Netherlands 2011.

26. Tran BX, Ohinmaa A, Nguyen LT. Quality of life profile and psychometric properties of the EQ-5D-5L in HIV/AIDS patients. Health Qual Life Outcomes 2012;10:132.

27. Tran BX, Ohinmaa A, Nguyen LT, et al. Determinants of healthrelated quality of life in adults living with HIV in Vietnam. AIDS Care 2011;23:1236-45.

28. Tran BX, Huong LT, Hinh ND, et al. A study on the influence of internet addiction and online interpersonal influences on healthrelated quality of life in young Vietnamese. BMC Public Health 2017:17:138

29. Tran BX, Nguyen LH, Nong VM, et al. Health status and health service utilization in remote and mountainous areas in Vietnam. Health Qual Life Outcomes 2016;14:85.

30. Tran BX, Nguyen LH, Phan HT, et al. Patient satisfaction with methadone maintenance treatment in Vietnam: a comparison of different integrative-service delivery models. PLoS One 2015;10:e0142644.

31. Tran BX, Vu PB, Nguyen LH, et al. Drug addiction stigma in relation to methadone maintenance treatment by different service delivery models in Vietnam. BMC Public Health 2016;16:238

32. Zhang MWB, Tran BX, Huong LT, et al. Internet addiction and sleep quality among Vietnamese youths. Asian J Psychiatr 2017;28:15-20 http://doi.org/.

33. Nguyen LH, Tran BX, Nguyen HLT, et al. Psychological distress among methadone maintenance patients in Vietnamese Mountainous Areas. AIDS Behav 2017;21:3228-37.

34. Nguyen T, Dennis $\mathrm{S}, \mathrm{An} \mathrm{H}$, et al. Psychological distress among Vietnamese adults attending Vietnamese-speaking general practices in South Western Sydney: prevalence and associations. Aust J Prim Health 2016;22.
35. Bradley KA, DeBenedetti AF, Volk RJ, et al. AUDIT-C as a brief screen for alcohol misuse in primary care. Alcohol Clin Exp Res 2007;31:1208-17.

36. Tran BX, Nguyen LT, Do CD, Cd D, et al. Associations between alcohol use disorders and adherence to antiretroviral treatment and quality of life amongst people living with HIV/AIDS. BMC Public Health 2014;14:27.

37. Tran BX, Nguyen N, Ohinmaa A, et al. Prevalence and correlates of alcohol use disorders during antiretroviral treatment in injection-driven HIV epidemics in Vietnam. Drug Alcohol Depend 2013;127:39-44.

38. Tran BX, Nguyen LH, Nguyen CT, et al. Alcohol abuse increases the risk of HIV infection and diminishes health status of clients attending HIV testing services in Vietnam. Harm Reduct J 2016;13:6.

39. Do HP, Nguyen LH, Thi Nguyen NP, et al. Factors associated with nicotine dependence during methadone maintenance treatment: findings from a multisite survey in Vietnam. BMJ Open 2017;7:e015889.

40. Tran BX, Nguyen LH, Do HP, Hp D, et al. Motivation for smoking cessation among drug-using smokers under methadone maintenance treatment in Vietnam. Harm Reduct J 2015;12:50.

41. Nong VM, Boggiano VL, Nguyen LHT, et al. Ability to join the workforce and work productivity among drug users under methadone maintenance treatment in a mountainous area of Northern Vietnam: a cross-sectional study. BMJ Open 2017;7:e016153.

42. Tran BX, Nguyen LH, Nguyen LP, et al. Methadone maintenance treatment promotes referral and uptake of HIV testing and counselling services amongst drug users and their partners. PLOS One 2016;11:e0152804.

43. Schafer JL. Multiple imputation: a primer. Stat Methods Med Res 1999;8:3-15.

44. Bennett DA. How can I deal with missing data in my study? Aust NZ $J$ Public Health 2001;25:464-9.

45. Donny EC, Brasser SM, Bigelow GE, et al. Methadone doses of $100 \mathrm{mg}$ or greater are more effective than lower doses at suppressing heroin self-administration in opioid-dependent volunteers. Addiction (Abingdon, England) 2005;100:1496-509.

46. Preston KL, Umbricht A, Epstein DH. Methadone dose increase and abstinence reinforcement for treatment of continued heroin use during methadone maintenance. Arch Gen Psychiatry 2000;57:395-404.

47. Teesson M, Ross J, Darke S, et al. One year outcomes for heroin dependence: findings from the Australian Treatment Outcome Study (ATOS). Drug Alcohol Depend 2006;83:174-80.

48. Luo X, Zhao P, Gong X, et al. Concurrent heroin use and correlates among methadone maintenance treatment clients: A 12-Month follow-up study in Guangdong Province, China. Int J Environ Res Public Health 2016;13:305.

49. Sullivan SG, Wu Z, Cao X, et al. Continued drug use during methadone treatment in China: a retrospective analysis of 19,026 service users. J Subst Abuse Treat 2014;47:86-92.

50. White WL, Campbell MD, Spencer RD, et al. Patterns of abstinence or continued drug use among methadone maintenance patients and their relation to treatment retention. J Psychoactive Drugs 2014:46:114-22.

51. Raffa JD, Grebely J, Tossonian H, et al. The impact of ongoing illicit drug use on methadone adherence in illicit drug users receiving treatment for HIV in a directly observed therapy program. Drug Alcohol Depend 2007;89:306-9.

52. Nguyen VT, Scannapieco M. Drug abuse in Vietnam: a critical review of the literature and implications for future research. Addiction 2008;103:535-43.

53. Senbanjo R, Wolff K, Marshall EJ, et al. Persistence of heroin use despite methadone treatment: poor coping self-efficacy predicts continued heroin use. Drug Alcohol Rev 2009;28:608-15. 